21.S2

\title{
Cografts of Adrenal Medulla With Pretransected Peripheral Nerve
}

\author{
I. Date, K. Sakai, Y. Hoshimoto, T. Furuta, S. Asari and T. Ohmoto \\ Department of Neurological Surgery, Okayama University Medical School, Okayama 700, Japan
}

\begin{abstract}
INTRODUCTION
It has been reported that adrenal medullary grafts enhance recovery of striatal dopamine (DA) fibers in MPTP-treated mice /1,2/. Since adrenal medullary chromaffin cells contain several trophic factors such as gangliosides and basic fibroblast growth factor, an increase in survivability of grafted chromaffin cells might enhance the degree of host DA fiber recovery. The content of nerve growth factor (NGF) in the distal stump of transected sciatic nerve increases more than twenty times one day after transection $/ 3 /$. In this study, we performed cografts of adrenal medulla with pretransected peripheral nerve and observed the survival of grafted chromaffin cells and the degree of host intrinsic DA fiber recovery.
\end{abstract}

\section{MATERIALS AND METHODS}

In all experiments, C57BL/6 male mice were used. Two month-old mice were used as recipients and one month-old mice were used as donors. Parkinsonian models were made by intraperitoneal injection of MPTP (4X20 $\mathrm{mg} / \mathrm{kg}$ ). Transplantation was performed into the right striatum one week after MPTP injection. Animals were divided into 6 groups: Group A (Control), i.p. injection of saline only; Group B (MPTP), i.p. injection of MPTP only; Group C (Sham), i.p. injection of MPTP and received sham operation one week later; Group D (Adrenal, i.p. injection of MPTP and received adrenal graft one week later; Group E (Nonpretransected), i.p. injection of MPTP and received cograft of adrenal medulla with nonpretransected sciatic nerve one week later; Group F (Pretransected), i.p. injection of MPTP and received cograft of adrenal medulla with pretransected sciatic nerve one week later. Pretransection of the sciatic nerve was performed one day before transplantation. All animals were sacrificed one month after transplantation and tyrosine hydroxylase (TH) immunocytochemistry and neurochemical analysis of dopamine using high performance liquid chromatography (HPLC) were performed.

\section{RESULTS}

In mice receiving adrenal medullary grafts alone (Group D), the mean number of surviving $\mathrm{TH}$ positive chromaffin cells was $65 \pm 12$ (mean \pm SEM, ranging from 30 to 101). In mice receiving cografts of adrenal medulla with nonpretransected (Group E) and pretransected (Group F) peripheral nerve, the mean number of surviving $\mathrm{TH}$ positive chromaffin cells was $120 \pm 14$ (ranging from 83 to 171 ) and $186 \pm 12$ (ranging from 150 to 220 ), respectively, significantly higher than that in mice in Group D.

$\mathrm{TH}$ immunocytochemistry revealed that the systemic injection of MPTP resulted in marked disappearance of $\mathrm{TH}$ positive fibers in the striatum. Computerized image analysis of host $\mathrm{TH}$ positive fibers showed that the density of $\mathrm{TH}$ positive fibers in mice in Groups D, E and F was significantly greater than that in the striatum of sham-operated mice (Group C) up to $900 \mu \mathrm{m}$ from the edge of the graft. However, the mice in Group F showed the most prominent $\mathrm{TH}$ positive fiber recovery in the area adjacent to the edge of the graft.

Determinations of DA concentrations 5 weeks after MPTP administration revealed marked depletion of DA in the striatum (Group $\mathrm{B}, 3114 \pm 561 \mathrm{ng} / \mathrm{g}$ ) compared to the vehicle treated control animals (Group A, 12456 \pm 1088 
ng/g). In sham-operated mice (Group C), the DA concentration $(3363 \pm 431 \mathrm{ng} / \mathrm{g})$ was not statistically different from that with MPTP treatment only. In mice with adrenal medullary grafts (Group D), DA concentration in the striatum recovered to $5232 \pm 326 \mathrm{ng} / \mathrm{g}$. DA concentrations in the mice with cografts (Group E and Group F) recovered to $5921 \pm 381$ and $6997 \pm 402$ $\mathrm{ng} / \mathrm{g}$, respectively, showing that mice in Group F recovered most prominently.

\section{CONCLUSION}

Cografting of adrenal medulla with pretransected peripheral nerve had a positive effect on the survivability of grafted chromaffin cells and this increased graft survivability enhanced the recovery of the host DA fibers. This grafting procedure might have a possible application in patients with Parkinson's disease. Experiments using aged animals and primate models are required.

\section{REFERENCES}

1. Bohn MC, Cupit L, Marciano F, Gash DM. Science 1987; 237: 913-916.

2. Date I, Felten SY, Olschhowka JA, Felten DL. Exp Neurol 1990; 107: 197-207.

3. Heumann R, Korsching S, Bandtlow C, Thoenen H. J Cell Biol 1987; 104: 1623-1631. 

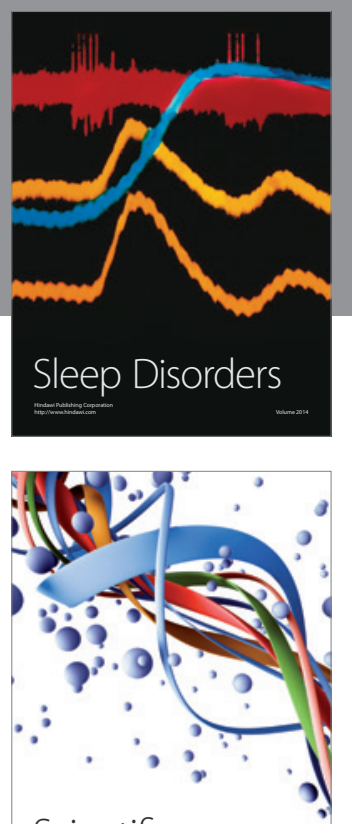

Scientifica
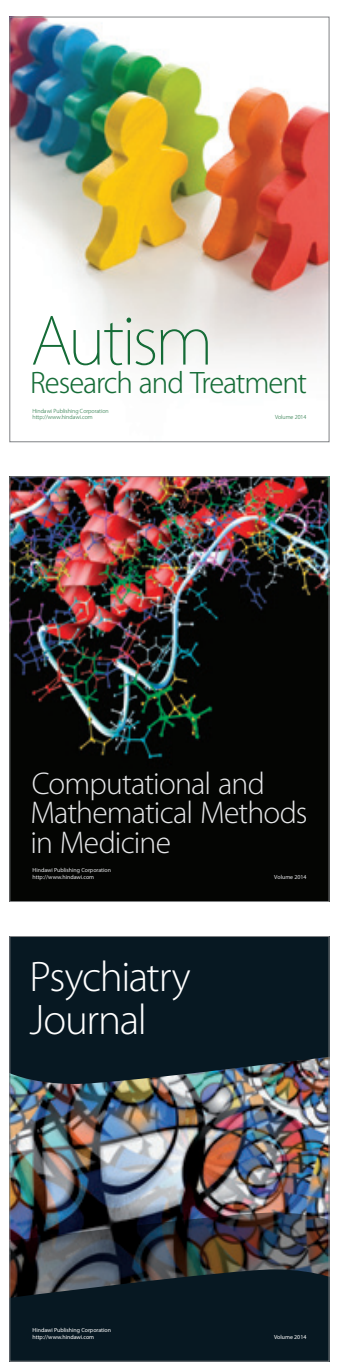
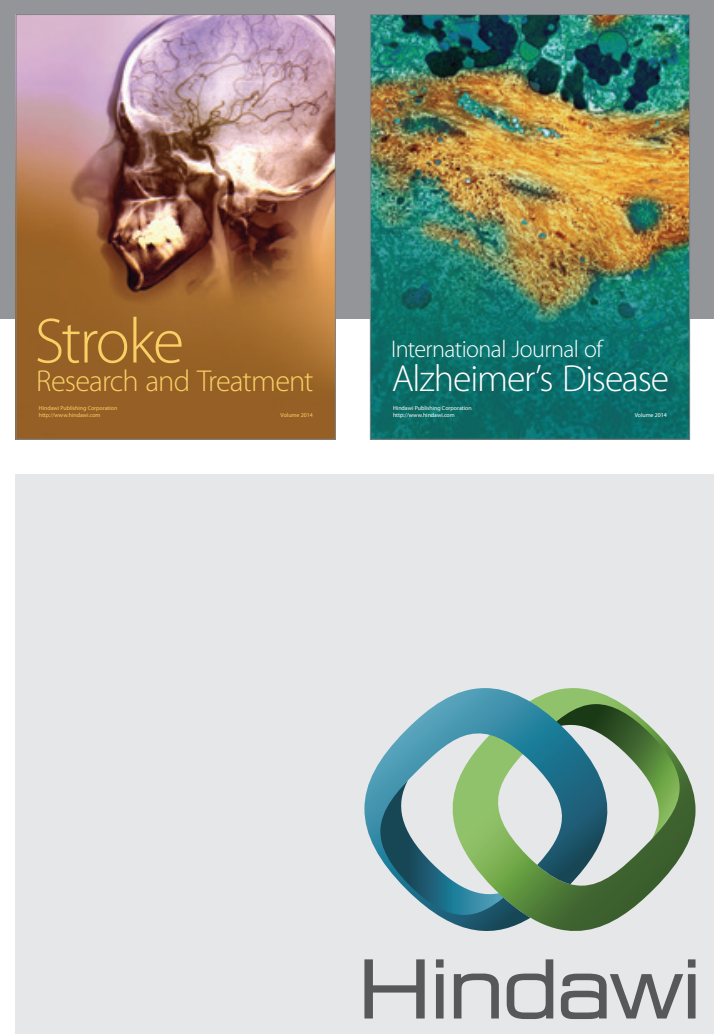

Submit your manuscripts at

http://www.hindawi.com
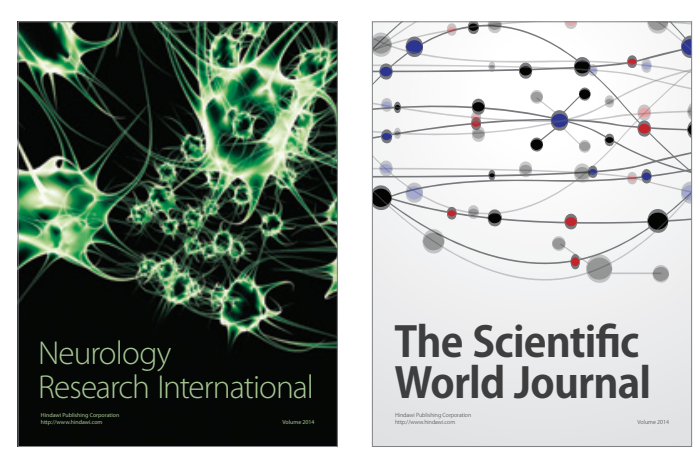

The Scientific World Journal

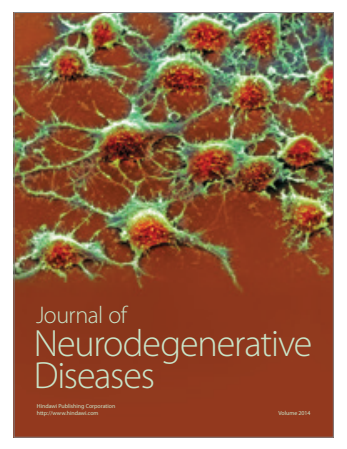

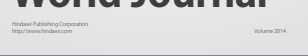

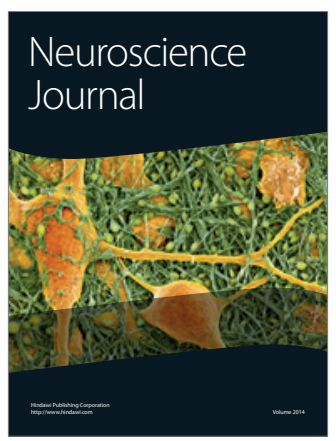

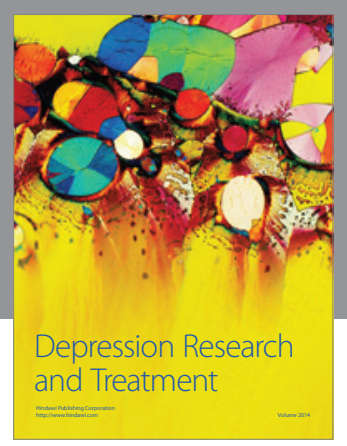
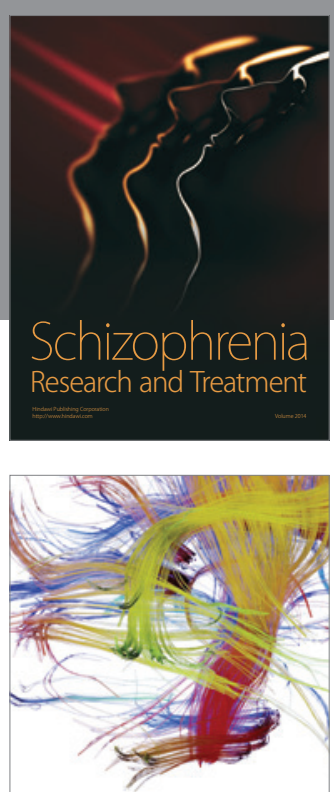

Brain Science

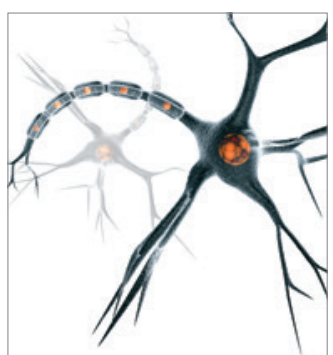

Neural Plasticity
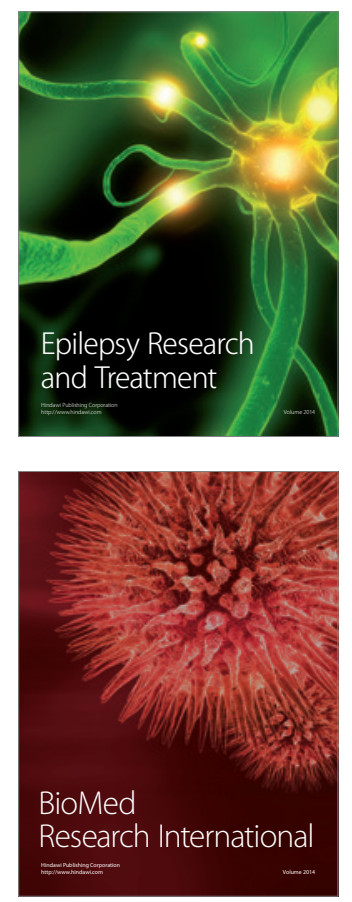

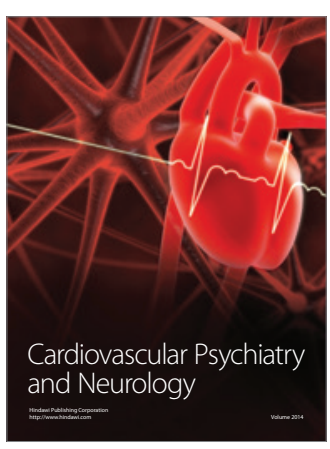

Parkinson's

Disease
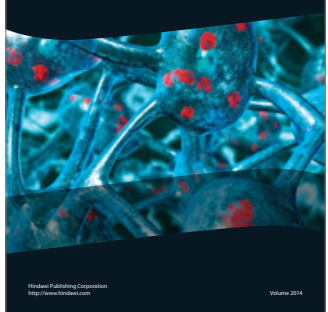